\title{
CONDE DE LAUTRÉAMONT: UMA PASSAGEM PARA A \\ FRANÇA
}

\section{COUNT OF LAUTRÉAMONT: A TICKET TO FRANCE}

\author{
Ruben Daniel Castiglioni ${ }^{1}$ e Janaína de Azevedo Baladão ${ }^{2}$
}

A poesia deve ser feita por todos.

(LAUTRÉAMONT, Os cantos de Maldoror)

\begin{abstract}
Resumo: Este artigo se propõe a incursionar na vida e na obra de Lautréamont. Nascido no Uruguai, no dia 4 de abril 1846, Isidore-Lucien Ducasse, nome de batismo de Lautréamont ou conde de Lautréamont, tornou-se um dos grandes escritores cultuados pelo movimento surrealista. De fato, Lautréamont é visto como sendo o precursor do movimento. Com base no "Estudo preliminar" à obra de Lautréamont, realizado por Pellegrini (2007), este artigo trata da vida e da obra lautreamontiana, no que tange o desencadeamento de um espírito de rebeldia, provocador da repulsa da ordem estabelecida na sociedade vigente.
\end{abstract}

Palavras-chave: conde de Lautréamont; Aldo Pellegrini; surrealismo; indivíduo e sociedade.

Abstract: This article proposes to cover into the life and work of Lautréamont. Born in Uruguay, on April 4, 1846, Isidore-Lucien Ducasse, baptismal name of Lautréamont or Count of Lautréamont, became one of the greatest writers worshiped by the surrealist movement. In fact, Lautréamont is seen as the precursor of the movement. Based on the "Preliminary Study" of Lautréamont's work by Aldo Pellegrini (2007), this article discuss the Lautreamontiana life and work, in what concerns to the triggering of a rebelliousness spirit, provoking the repulsion of the established order in the current society.

Keywords: Count of Lautréamont; Aldo Pellegrini; surrealism; individual and society.

\section{Considerações iniciais}

Lautréamont ou conde de Lautréamont é um nome emblemático para o surrealismo. Por vezes não compreendido, mas cultuado por muitos, certo é que não se furtou de deixar sua marca para a posteridade. Les Chants de Maldoror, publicado pela

\footnotetext{
${ }^{1}$ Professor Titular do Instituto de Letras da Universidade Federal do Rio Grande do Sul. Bolsista de Produtividade em Pesquisa do CNPq.

2 Tradutora, doutora em Letras (Universidade Federal do Rio Grande do Sul) e professora da Pontifícia Universidade Católica do Rio Grande do Sul.
} 
primeira vez em 1868 (o primeiro canto, de forma anônima), nas palavras de André Breton (1997, p. 151-2), ${ }^{3}$ um dos fundadores do surrealismo, "brilham com um fulgor incomparável: são a expressão de uma revelação total, que parece exceder as possibilidades humanas". Os elogios não cessam: Antonin Artaud (1965, p. 125) ${ }^{4}$ definia como sendo, "sem dúvida, um gênio irredutível para o mundo, e não menos desejável para o mundo do que Edgar Poe, Baudelaire, Gérard de Nerval ou Arthur Rimbaud”. Octavio Paz (2012, p. 259) ressalta também a importância de Lautréamont: "A história da poesia moderna é a história de uma desmedida. Todos os seus grandes protagonistas, depois de desenhar um sinal breve e enigmático, estatelaram-se contra a rocha. O astro negro de Lautréamont rege o destino de nossos mais altos poetas". E ainda: "Lautréamont consuma a ruína do discurso da demonstração. Nunca foi tão completa a vingança da poesia" (PAZ, 2012, p. 90).

Já é muito conhecida a definição de André Breton para o que vem a ser o surrealismo. No Manifesto, de 1924, diz que o movimento deve ser entendido da seguinte forma: "Automatismo psíquico em estado puro mediante o qual se propõe exprimir, verbalmente por escrito ou por qualquer outro meio, o funcionamento do pensamento" (BRETON, 2001, p. 40). Breton, como explica Robert Ponge (1999, p. 11), nesse Manifesto, "lançava um autêntico grito de revolta, de não conformismo e de liberdade, exaltava o maravilhoso e o poder da imaginação, chamava a 'praticar a poesia' e a mudar a vida". ${ }^{5}$ Nesse sentido, podemos dizer que a crença de que a arte não tem uma função em si, mas sim o dever de expressar tudo o que é vital para o ser humano marca o surrealismo. Aldo Pellegrini (2012, p. 16), ${ }^{6}$ no estudo inicial de sua Antología de la poesia surrealista, diz que, para os surrealistas, "arte e vida formam uma unidade". Efetivamente, os artistas que se reuniram no início da década de $20 \mathrm{em}$ torno da revista Littérature alertavam sobre a imperiosa necessidade de mudança da vida, colocando em pauta questões sobre o homem e a condição humana que ultrapassavam a barreira da arte. Nesse sentido, a preocupação se dirigiu ao homem concreto, ou seja, havia uma inquietação centrada no desafio de conhecer, de fato, quais eram as necessidades e desejos do ser humano, mapeando os sonhos e paixões, "diante de uma sociedade artificial, regida por normas éticas e sociais absurdas, de uma

\footnotetext{
3 Tradução nossa.

${ }^{4}$ Tradução nossa.

${ }^{5}$ Grifos do autor.

${ }^{6}$ Todas as demais citações desta obra são traduções nossas do espanhol ao português.
} 
sociedade mecanizada e hipócrita, com valores arbitrários e falsos" (PELLEGRINI, 2012, p. 15).

Sabemos que o surrealismo não se restringiu à França, como alerta Willer (2008, p. 283), mas teve Paris como sua vertente cosmopolita, que uniu e reuniu várias personalidades pertencentes ou não à literatura, em nome das vanguardas europeias, no início do século XX. Para Willer (2008, p. 284), o "surrealismo representou ruptura, e também continuidade. Não surgiu do nada. Por isso, especialmente através de André Breton, indicou antecessores e genealogias". No primeiro Manifesto do surrealismo, Breton (2001, p. 41) cita Isidore-Lucien Ducasse, o conde de Lautréamont, como um precursor do movimento, "um caso fascinante". No segundo Manifesto, lançado em 1930, Breton (2001, p. 200) se ocupa longamente de Maldoror e diz que Lautréamont é um escritor inatacável. Daí vem o que poderíamos pensar como a filiação de Lautréamont ao movimento, poeta que já havia falecido quase 54 anos antes da chegada do primeiro Manifesto. Em relação à América, entre outros expoentes, Aldo Pellegrini tomou para si a tarefa de impulsionar o movimento surrealista. E é a partir de sua visão que passaremos a falar sobre Lautréamont e a sua obra, no que tange, sobretudo, o desencadeamento de um espírito de rebeldia e provocador da repulsa da ordem estabelecida na sociedade vigente.

\section{Sobre Pellegrini}

O surrealista argentino Aldo Pellegrini nasceu em 1903, em Rosário, cidade a quase trezentos quilômetros de Buenos Aires, capital da Argentina. Ainda era um jovem estudante de medicina quando criou, em 1926, o primeiro grupo de surrealistas fora da França, em língua espanhola. Nessa época, fundou a revista Qué (1928) e também dirigiu as revistas Ciclo (1948-1949), A partir de cero (1952-1954), Letra y línea (19531954) e La Rueda (1967). Escritor comprometido com sua poética, Pellegrini também nos deixou como herança o drama Teatro de la inestable realidad, publicado em 1964, e o ensaio Para contribuir a la confusión general, em 1965, obras sem tradução ao português. Da mesma forma, aventurou-se na poesia. Temos conhecimento até o presente momento da existência de cinco livros: El muro secreto (1949), La valija de fuego (1953), Construcción de la destrucción (1957), Distribución del silencio (1966) e Escrito para nadie, obra inédita do início da década de 70, publicada postumamente em 1989, também sem tradução ao português. Na década de 60, organizou sistematicamente 
três antologias, a saber: La Antología de la poesía surrealista de la lengua francesa (1961); a antologia de Oliverio Girondo (1964); e a Antología de la poesía viva de Latinoamérica (1966).

Entre outras publicações e atividades, cabe destacar as traduções de Pellegrini ao espanhol de obras que promoveram o movimento vanguardista. A lista de traduções e referências a traduções de Pellegrini é considerável, mas nos atemos ao ponto que aqui nos interessa: Lautréamont. Em 1964, Pellegrini lançaria o livro de tradução com as obras completas do poeta maldito. Essa tradução é considerada a versão definitiva ao espanhol da obra de Lautréamont. Essa escolha da obra lautreamontiana não é em vão. Seguindo os estudos de Aldo Pellegrini (1950, 297-8), ${ }^{7}$ Lautréamont pode ser pensado também de maneira histórica, já que o surrealismo, “colocado no fluir histórico, constitui-se na culminação de um movimento espiritual com profundas raízes no passado". Seguindo os estudos de Pellegrini (1950, p. 297), o surrealismo pode ser visto, então, como herdeiro do passado e como expressão do presente. Mas não todo passado, apenas aquele no qual o surrealismo se reconhece. Lautréamont, sem dúvida, faz parte desse passado histórico e filia-se também à aura desse movimento espiritual. Por fim, vale lembrar que Pellegrini (1950, p. 309) não poupa elogios à obra, em suas palavras: "a imaginação livre, o furor, o sarcasmo, o lirismo, tudo isso levado à máxima exaltação, fazem dos Cantos de Maldoror uma das máximas obras do espírito do homem".

\section{Sobre Lautréamont}

Filho de pais franceses, Isidore-Lucien Ducasse, seu nome de batismo, nasceu no dia 4 de abril de 1846, durante a ocupação das tropas de Juan Manuel de Rosas em Montevidéu. O cenário político não era muito favorável: desde 1839 havia estourado a "Guerra Grande", conflito bélico que se seguiu por mais de uma dezena de anos, na qual se enfrentariam "los blancos", apoiados pelo Paraguai e pelos federalistas argentinos, e "los colorados", apoiados pelo império brasileiro. O Uruguai, como afirma Monteiro (2016, p. 28), tornava-se o grande alvo de disputas entre os interesses da Argentina de Rosas e do Brasil de Dom Pedro. Em Os cantos de Maldoror, Lautréamont (2015, p. 106) faz referência à origem:

\footnotetext{
${ }^{7}$ Todas as demais citações desta obra são traduções nossas do espanhol ao português.
} 
O final do século dezenove verá seu poeta (entretanto, no começo ele não deve apresentar uma obra-prima, mas seguir a lei da natureza); ele nasceu em litorais americanos, na embocadura do Prata, ali onde dois povos, outrora rivais, agora se esforçam para ultrapassar-se no progresso material e moral. Buenos Aires, a rainha do Sul, e Montevidéu, a elegante, estendem-se as mãos amigas através das águas prateadas do grande estuário. Mas a guerra eterna instalou seu império destruidor sobre os campos, e ceifa com alegria inumeráveis vítimas.

A vida solitária do poeta estaria marcada também pela morte prematura da mãe: Lautréamont tinha menos de dois anos quando Célestine-Jacquette Davezac faleceu. O pai, Francisco Ducasse, na época, estava vinculado ao consulado geral da França no Uruguai. Montevidéu já era, então, uma terra que abrigava muitos estrangeiros. Domingo Faustino Sarmiento (2017, p. 37), em suas viagens pelos continentes, estimou que, no ano de 1843, habitavam em Montevidéu 11.431 orientais, 3.170 americanos, 15.252 europeus e 1.344 africanos livres. E é nesse entorno em que viveria Lautréamont até seus 14 anos, quando partiu para a França.

Pellegrini (2007, p. 11) afirma que é possível seguir os passos do poeta graças às pesquisas de Alicot e de Genonceaux. Sabemos, então, que Ducasse aportou em solo francês em 1860 e logo foi inscrito como aluno interno no liceu imperial de Tarbes, região de nascimento de seu pai, onde permaneceu durante três anos até sua ida ao liceu de Pau. Lautréamont vai se dirigir a Paris apenas no ano de 1865, para estudar na escola politécnica. Nesse período, era comum encontrá-lo sentado ao piano declamando seus versos. "Habitualmente triste e silencioso", 8 como definiu um colega de liceu, Lautréamont era, para Pellegrini (2007, p. 13), ${ }^{9}$ uma "estranha figura que parece ter passado pela vida sem viver, como um espectador ao mesmo tempo horrorizado e brincalhão que nos deixou, como herança de sua obscura viagem pelo mundo, uma violenta acusação contra o homem".

Em agosto de 1868 apareceu o primeiro canto de Maldoror, publicado anonimamente e assinado com três asteriscos. Um ano depois, com a ajuda de Albert Lacroix, o autor editava a versão completa de seus cantos, constituída de sessenta estrofes, já com o nome de conde de Lautréamont, que se transformaria em seu alter ego literário. ${ }^{10}$ De acordo com Pellegrini (2007, p. 14), Lautréamont recebeu vinte

\footnotetext{
${ }^{8}$ Alicot publicou em 1928 o depoimento de Paul Lespés, colega de Lautréamont no Liceu de Pau. Para mais informação, ver o depoimento transcrito em Os cantos de Maldoror, poesias, cartas - obras completas (LAUTRÉAMONT, 2015, p. 341-8).

${ }^{9}$ Todas as demais citações desta obra são traduções nossas do espanhol ao português.

${ }^{10}$ Uma das teorias sobre o nome de Lautréamont se refere ao fato da existência de um livro chamado Latréaumont, do autor de folhetins Eugène Sue. Há uma alteração na ortografia (Latréaumont x Lautréamont), mas a essência parece ser a mesma. O título de conde, por sua vez, estaria relacionado ao famoso e polêmico Marquês de Sade.
} 
exemplares, mas essa edição não foi posta em circulação, já que Lacroix, continuamente perseguido por suas posições, temia por retaliações. Somente em 1874 apareceu em Bruxelas uma edição póstuma, mas o editor belga Jean-Baptiste Rozez também não se atreveu a fazer a distribuição, alegando que o livro estava envolto em uma "violência da linguagem" sem precedentes (PELLEGRINI, 2007, p. 14). Curiosamente, somente onze anos após essa primeira tentativa em terras estrangeiras, Rozez iria mostrar o livro a Max Waller, do grupo literário La jeune Belgique, que o considerou um texto divertido. Conforme explicita Pellegrini (2007, p. 14), foi Iwan Gilkin, poeta integrante desse grupo, que proclamou que se tratava de uma obra genial. A partir de então, vários de seus amigos leram o livro, que foi enviado novamente à França.

Em 1870, assinando como Isidore Ducasse, veio à luz o exemplar intitulado Poesias, no qual o poeta franco-uruguaio se propunha a iniciar um caminho novo em relação à obra Os cantos de Maldoror. Vale lembrar que a primeira edição na íntegra de Poesias foi publicada na já citada revista Littérature, a cargo de Breton, com o prefácio de Philippe Soupault. Lautréamont faleceu em 24 de novembro de 1870, aos 24 anos, em Montmartre, Paris. Sobre ele, então, é válido dizer que tentou resistir ao espírito de seu tempo, designado por Chateaubriand como "mal do século", cujos sintomas apontavam para certo desespero e incredulidade no futuro. Em duas cartas de Lautréamont (2015, p. 336-8), datadas no início de 1870, ele se refere a essa melancolia: (1) "Canto apenas a esperança; mas para isso, é preciso atacar a dúvida deste século (melancolia, tristezas, orgulhos pueris, maldições engraçadas, etc., etc.)"; ${ }^{11}$ (2) "Os gemidos poéticos deste século não passam de sofismas horrendos. Cantar o tédio, as dores, as tristezas, as melancolias, a morte, a sombra, o sombrio, etc., é só querer, a qualquer preço, encarar o avesso pueril das coisas". ${ }^{12}$ Ironicamente, neste mesmo ano em que morreria de causa não conhecida (há uma hipótese de suicídio), Lautréamont (2015, p. 339) ${ }^{13}$ se propõe a "cantar exclusivamente a esperança, A CALMA, a felicidade, O DEVER”. Pellegrini (2007, p. 22) afirma que Lautréamont sofreu e sentiu na pele "esse clima de rebelião, de desprezo por um conformismo que se personificou no chamado espírito burguês, de ruptura com o cotidiano e preferência pela aventura e fantasia".

\footnotetext{
Outra possibilidade aventada é a combinação da palavra l'autre (“o outro"), mais a proposição "a”, que, nesse caso, indica lugar, e a raiz mont (possivelmente uma referência a Montevidéu ou a Montparnasse). O sentido dessa combinação nos levaria à formulação "o outro de Montevidéu" ou "o outro de Montparnasse", mostrando a divisão ou a união de dois universos: a terra onde nasceu e a terra onde escolheu viver.

${ }^{11}$ Carta sem destinatário definido, datada em 21 de fevereiro de 1870, em Paris, assinada como I. Ducasse.

${ }^{12}$ Carta dirigida a Darasse, datada em 12 de março de 1870, em Paris, assinada como I. Ducasse.

${ }^{13}$ Grifos do autor.
} 


\section{$4 O$ olhar de Pellegrini em relação à obra de Lautréamont: aproximações insólitas}

O estudo preliminar que realizou Pellegrini da obra de Lautréamont está datado em Buenos Aires, 30 de março de 1962. Ocupa quase um quarto da obra no total e abrange os seguintes tópicos, assim intitulados: Biografia de Isidore Ducasse (conde de Lautréamont); História de Os cantos de Maldoror; Os comentaristas; As influências sobre Lautréamont; A influência de Lautréamont na literatura posterior; A claridade de uma obra obscura; Deus e o problema do mal; A condição humana; O grande objeto exterior; A solidão e o orgulho; O espírito de rebeldia; O pessimismo construtivo; As Poesias e a negação da negação; Os símbolos; Motivações psicológicas; As estruturas antagônicas; O aspecto formal de Os cantos de Maldoror; O humor; Significado da comunicação poética; Alcances da mensagem poética de Lautréamont; e A obra de Lautréamont é um mundo aberto.

A enumeração dos títulos já nos mostra a grande preocupação de Pellegrini (2007) com o mapeamento e o alcance da obra de Lautréamont. Não era a primeira vez que Pellegrini se debruçava sobre a obra de Lautréamont, nem seria a última. Na segunda edição da revista Ciclo, lançada em 1949, nos textos sobre a liberdade do artista também são referenciados os aspectos da vida de Lautréamont. Em Para contribuir a la confusión general, Pellegrini (1965, p. 59) reitera e celebra a importância das escolhas literárias de Lautréamont que, apesar de lançar o poeta a uma guerra total causando sua própria destruição, fez com que ele se aproximasse a um seleto grupo que viveu de "modo autêntico".

Pellegrini (2007, p. 9), em seu estudo sobre a obra lautreamontiana, reconhece que a leitura de Maldoror é um desafio, na medida em que não segue regras vigentes nem mantém o chamado "bom gosto", estabelecendo, além de tudo, uma desorientação ao leitor já em suas primeiras linhas, mas que, se superada, “oferece o mais maravilhoso espetáculo que a linguagem pode dar”. Essa impressão não se restringe à palavra, para o surrealista argentino, todos os cantos de Maldoror "respondem a uma realidade mais profunda e essencial, que corresponde à verdadeira natureza do homem [...]" (PELLEGRINI, 2007, p. 9).

De maneira esquemática, a obra está dividida em seis cantos com estrofes aparentemente independentes, que se unem com o propósito de "atacar, por todos os meios, o homem, essa besta-fera, e o Criador, que não deveria ter engendrado 
semelhante inseto" (LAUTRÉAMONT, 2015, p. 115). Vista de maneira geral, forma uma paródia da estrutura em relação às epopeias clássicas, estendendo-se ao uso sarcástico dos epítetos homéricos. Além disso, vale-se das prosopopeias e cada canto se inicia com um exórdio ao leitor com explicações sobre o que se está lendo. Segundo Pellegrini (2007, p. 60), o poema apresenta uma forma labiríntica, já que os diálogos oscilam entre a severidade dantesca e a solenidade ridicularizada do folhetim. Da mesma forma, é interessante notar que há uma sequência de hinos, reflexões sobre o ser humano, considerações sobre Deus, misturada a comparações absurdas e blasfêmias de todos os tipos. Em contrapartida, em meio a esse emaranhado, a obra maldororiana nos oferece um humor e uma musicalidade que se apoiam na alternância de ritmos muito bem articulados nas frases. Como diz textualmente Pellegrini (2007, p. 61):

\begin{abstract}
Lautréamont oferece pela primeira vez a imagem absolutamente gratuita, ou melhor, ilógica, eliminando todos os fios condutores racionais. Essa imagem que se separa da metáfora aparece como um produto espontâneo e puro da fantasia, sem utilidade nem razão aparente, mas dotada de um caráter inesperado, de uma vitalidade agressiva ou de um curioso conteúdo emocional, que não pode ser alcançado por meio de nenhum tipo de exposição racional. Esse mecanismo recebe o nome de aproximações insólitas e é possível dizer que Lautréamont foi o inventor desse achado poético que teve grande difusão na poesia moderna, especialmente adotado pelos surrealistas, e que consiste na reunião de duas realidades muito afastadas entre si.
\end{abstract}

Ao analisar as técnicas surrealistas, Pellegrini (2012, p. 24) chama a atenção sobre o fato de que foi a partir da famosa frase de Lautréamont $(2015$, p. 252) sobre o belo, "o encontro fortuito sobre uma mesa de dissecção de uma máquina de costura e um guarda-chuva", que se passou a pensar nas "aproximações insólitas". Essas aproximações, que captam relações que vão além da razão, levariam o leitor a perceber um "símbolo da união dos contrários, da identidade dos opostos", como bem explicou Pellegrini (2012, p. 24). O surrealismo está intimamente ligado à obra de Lautréamont, como já dito antes. Nas palavras de Breton (2001, p. 2010) ${ }^{14}$ :

Lautréamont começa por prevenir o leitor de que "a não ser que ele se disponha a lê-lo com uma lógica rigorosa e uma tensão anímica quando menos igual à sua desconfiança, as emanações mortais deste livro - Os Cantos de Maldoror - penetrar-lhe-ão a alma, como a água penetra o açúcar", mas tem o cuidado de acrescentar que "somente alguns saborearão este fruto amargo sem perigo”. Esta questão da maldição, que até o presente praticamente só deu ensejo a comentários irônicos ou irrefletidos, é, mais do

\footnotetext{
${ }^{14}$ Grifos do autor.
} 
que nunca, atual. O surrealismo só tem a perder se quiser afastar de si tal maldição.

E aqui tocamos em outro ponto em comum com os pressupostos surrealistas: o humor negro. Uma das principais armas da poesia, como espírito de revolta, é o humor, que constitui um dos valores fundamentais do surrealismo, sendo uma arma eficaz para atacar as convenções sociais. Humor seria o oposto da amabilidade, também se diferenciando do irônico que, para Pellegrini (2007, p. 63), é um "mero jogo intelectual”. Ainda que possa zombar de tudo o que é solene, o humor é o sentimento mais sério que existe ao colocar o indivíduo no centro dos problemas. Por esse motivo, “o humor não é alegre, é angustiante, e frequentemente é a roupagem perfeita do pessimismo mais profundo" (PELLEGRINI, 2007, p. 63). Pode-se sintetizar o conceito da seguinte forma:

O humor representa o protesto contra a ordem convencional. É a manifestação mais nítida do inconformismo. Revela a máxima ação corrosiva do espírito sobre a máscara de um mundo artificial, hipócrita e convencional, ao qual desintegra e anula. Diante do humor, rompem-se normas e princípios que pareciam inabaláveis, evidenciando o sistema de falsos valores que nos governa. O humor atua sobre a segurança do espectador comovendo todos seus fundamentos. Em sua categoria extrema, o "humor negro" adquire aspectos de ferocidade e crueldade inigualáveis. De todos os valores - afirma Breton -, o humor revela uma ascensão constante. É, sem sombra de dúvida, a característica mais específica da sensibilidade moderna. Alimenta-se de todas as formas do arbitrário e do absurdo, e é possível afirmar que, independentemente da forma, não há texto poético surrealista autêntico em que não esteja presente. (PELLEGRINI, 2012, p. 27-8)

Contudo, o humor negro, categoria extrema do humor, pode provocar destruição e aniquilação. E Lautréamont, de fato, vale-se desse recurso em sua obra ao colocar em evidência a burla exagerada, a violência arbitrária e grotesca. Conforme analisa Pellegrini (2007, p. 64), em Maldoror, o humor preside desde a metamorfose e a transformação delirante até as observações metafóricas, seja no que se refere à paródia a Dante, seja no que tange à paródia aos folhetins mais pueris. Nesse jogo, o texto oscila entre o plágio, a demonstração científica e o absurdo de um transbordamento que beira ao delírio. Para o escritor argentino, esse caráter variável e extraordinariamente dinâmico da obra lautreamontiana dá um aspecto de mar agitado muitas vezes, mas também de sutis ondulações de humor lírico. Se tomarmos a narrativa como um todo, podemos perceber que a curva de humor em Maldoror cresce exponencialmente até o canto III, quando a violência alcança seu ápice. No canto seguinte, há fragmentos de 
humor burlesco, enquanto, no canto $\mathrm{V}$, a violência se atenua, apesar das aproximações insólitas, até chegar ao canto VI com a crueldade fria, que se esconde em uma "irônica objetividade do relato" (PELLEGRINI, 2007, p. 64).

Efetivamente, Lautréamont imprime uma expressiva carga emocional em seu texto. Pellegrini (2007, p. 35) destaca justamente a condição humana vista a partir de $O s$ cantos de Maldoror e a forma como a responsabilidade dos males que o mundo sofre recai no ser humano. A obra de Lautréamont, nesse sentido, é um "grande clamor de protesto contra a condição humana tal qual está posta”, entendendo aqui a condição humana como a situação do indivíduo em seu meio social e o convívio com seu semelhante (PELLEGRINI, 2007, p. 36). Para Pellegrini (2007, p. 37), a conduta do ser humano "está regulamentada por uma estrutura moral que Lautréamont considera degradada, já que o homem se sente atraído pelo vício e pela crueldade”. Mas nem sempre foi assim. $\mathrm{O}$ ser humano nasce envolto à pureza e inocência. É a estrutura do mundo adulto que impõe a hipocrisia como modo de vida. Viver, então, como explica Pellegrini (2007, p. 36), "significa a paulatina destruição da inocência, fonte do amor. Esse é o doloroso sentido da existência que formula Lautréamont". A hipocrisia, portanto, desfaz todos os esforços possíveis abrindo espaço para a moral vigente, que é anti-humana e abstrata, quando, na verdade, a verdadeira moral deveria ater-se à raiz vital ligando-se essencialmente ao amor (PELLEGRINI, 2007, p. 37).

O cenário maldororiano apresenta uma sequência de desvio, violência, perversão e crueldade. Pellegrini (2007, p. 37) associa a crueldade à tentativa de aniquilação da inocência que tanto a criança como o adolescente, em geral, personificam. Em suas palavras: a "inocência [em Maldoror] é resultado de uma ilusão, um elemento estranho nesse mundo corrompido [...]. Ou o inocente é atraído até o mal mediante a persuasão, ou deve ser suprimido porque sua existência não tem sentido" (PELLEGRINI, 2007, p. 38). É no próprio início dos cantos que nos deparamos com a cena da criança que, não inclinada a cometer o mal, é aniquilada; ou mais adiante, no canto III, quando há uma violação de uma menina; ou o filho torturado pelos pais, no canto IV. Como diz Pellegrini (2007, p. 38), são crimes contra seres amados ou que podem ser amados. Mas o amor não tem sentido em um mundo repleto de ódio e egoísmo. Em meio ao caos, nesses episódios nos quais a violência prevalece, há uma esperança: a piedade. "Essa associação de dois elementos contraditórios, a crueldade e a piedade, corresponde à presença permanente dos antagonistas que caracteriza a obra de Lautréamont", define Pellegrini (2007, p. 39). 


\section{Considerações finais}

O indivíduo que se vê condenado à solidão, como é o caso de Lautréamont, diz Pellegrini (2007, p. 41), sente a impulsão de afirmar sua individualidade de maneira distinta ao que a sociedade lhe impõe. A solidão do artista acentua a criação de um universo fantástico, por onde transita Maldoror, que provoca a revolta. Como lembra Pellegrini (2007, p. 41), a temática dos românticos está configurada pela presença da solidão, da fantasia e da revolta também, mas sem a violência exacerbada. Nesse viés, Lautréamont rompe com essa noção de medida "para impor a nova noção de desmesura" (PELLEGRINI, 2007, p. 41). Vale dizer que "Lautréamont se ergue como acusador da sociedade, de suas instituições e de sua moral. Sua não aceitação é total. Toda a sua poesia proclama revolta" (PELLEGRINI, 2007, p. 43).

A obra de Lautréamont pede passagem. Não estranha o fato de não ter encontrado eco imediato na França, em uma época voltada para questões formais da poesia, dominada pelos parnasianos. Precisou primeiro fazer um périplo pela Bélgica para voltar à França. Na América de Isidore-Lucien Ducasse, Rubén Darío havia feito uma menção em Los raros, em 1896, obra que reúne uma série de autores admirados pelo poeta nicaraguense. A obra Os cantos de Maldoror foi traduzida ao espanhol em 1924, como confirma Willer (2015, p. 23), sendo adotada por Federico García Lorca, Rafael Alberti e Pablo Neruda. Contou com a aceitação de Alfred Jarry e Marcel Schwob, além de Paul Fort, que publicou um fragmento em sua revista em 1914. Mas a influência fundamental, conforme explica Pellegrini (2007, p. 29), ocorreu entre os jovens poetas franceses da década de 20, na época envolvidos com o dadaísmo, mas, que mais tarde, fundariam o surrealismo. Nesse grupo, a obra lautreamontiana encontrou "o meio apto para a ação fecundante: a rebeldia exacerbada contra todas as normas convencionais" (PELLEGRINI, 2007, p. 29). Ou seja, se "não fosse evidente que toda a aparição avassaladora de um estado de espírito coletivo é inevitável, iria parecer que o surrealismo é o herdeiro direto de Lautréamont, em virtude de tanta coincidência no espírito, na intenção e na forma" (PELLEGRINI, 2007, p. 29). Por fim, Lautréamont parece fazer parte de um "grande elo que se estende no tempo através da história”, ou seja, parece fazer parte de um conjunto de indivíduos que estão unidos em "uma luta incessante, contra uma corrente poderosíssima que tende a anular o homem 
como ser vital, prometendo-lhe [...] uma utópica segurança no presente ou uma recompensa futura" (PELLEGRINI, 2007, p. 29).

\section{REFERÊNCIAS}

A partir de cero. Dirigente: Enrique Molina. Buenos Aires, n. 1, nov. 1952; n. 2, dez. 1952; n. 3, set. 1956. (Revista exclusivamente surrealista).

ARTAUD, Antonin. Anthology. São Francisco: City Lights Books, 1965.

BRETON, André. Manifestos do surrealismo. Tradução de Sergio Pachá. Rio de Janeiro: Nau, 2001. 1997.

Antología del humor negro. Tradução de Joaquín Jordá. Barcelona: Anagrama,

CASTIGLIONI, Ruben Daniel Méndez. Surrealismo. Aldo Pellegrini: el pionero en América. Porto Alegre, Instituto de Letras, Universidade Federal do Rio Grande do Sul, 2014.

Ciclo. Dirigentes: Aldo Pellegrini; Enrique Pichon Rivière. Buenos Aires, n. 1, nov. 1948; n. 2, mar. 1949. (Revista de reunião de surrealistas e artistas concretos - estes últimos representados por Tomás Maldonado).

La rueda. Direção coletiva: Aldo Pellegrini; Carlos Latorre; Julio Llinás; Francisco Madariaga; Edgar Bayley; Enrique Molina. Buenos Aires, n. 1, jul. 1967.

LAUTRÉAMONT, Conde de. Os cantos de Maldoror: poesias, cartas, obra completa. Tradução de Claudio Willer. São Paulo: Iluminuras, 2015.

Letra y línea. Dirigente: Aldo Pellegrini. Buenos Aires, n. 1, out. 1953; n. 2, nov. 1953; n. 3, dez. 1953; n. 4, jul. 1954. (Revista do grupo surrealista que convoca intelectuais de outros setores).

MONTEIRO, Alexandre Borella. A Guerra Grande: história e historiografia do conflito no Prata (1864-1870). Porto Alegre: FCM, 2016. [Coleção Mar del Plata]

PAZ, Octavio. O arco e a lira. Tradução de Ari Roitman e Paulina Wacht. São Paulo: Cosac Naify, 2012.

PELLEGRINI, Aldo. La poesía surrealista. In: PELLEGRINI, Aldo. Antología de la poesía surrealista. Buenos Aires: Argonauta, 2012.

El conde de Lautréamont y su obra. In: LAUTRÉAMONT, Conde de. Obras completas: los cantos de Maldoror, poesías, cartas. Buenos Aires: Argonauta, 2007.

Escrito para nadie. Buenos Aires: Argonauta, 1972. 
. Antología de la poesía viva latinoamericana. Barcelona: Seix Barral, 1966.

. Distribución del silencio. Buenos Aires: Argonauta, 1966.

. Para contribuir a la confusión general. Buenos Aires: Nueva Visión, 1965.

. Oliverio Girondo. Antología. Buenos Aires: Argonauta, 1964.

. Teatro de la inestable realidad. Buenos Aires: Carro del Tespis, 1964.

. Construcción de la destrucción. Buenos Aires: A partir de cero, 1957.

. La valija de fuego. Buenos Aires: Americalee, 1952.

. El movimiento surrealista. Cursos y conferencias. Buenos Aires, [s/ed.]: 1950.

. El muro secreto. Buenos Aires: Argonauta, 1949.

. La conquista de lo maravilloso, Ciclo, Buenos Aires, n. 2, p. 51-70, 1949.

PONGE, Robert (Org.). Surrealismo e novo mundo. Porto Alegre: Editora da

Universidade Federal do Rio Grande do Sul, 1999.

Qué. Dirigente: Aldo Pellegrini. Buenos Aires, n. 1, nov. 1928; n. 2, dez. 1930. (Revista exclusivamente surrealista - Primeira em espanhol).

SARMIENTO, Domingo Faustino. Viajes por Europa, África y América 1845-1848. Barcelona: Red, 2017.

WILLER, Claudio. O astro negro. In: LAUTRÉAMONT, Conde de. Os cantos de Maldoror: poesias, cartas, obra completa. Tradução de Claudio Willer. São Paulo: Iluminuras, 2015.

. Surrealismo: poesia e poética. In: GINSBURG, J.; LEIRNER, Sheila (Orgs.).

O surrealismo. São Paulo: Perspectiva, 2008. 